\title{
Advances in boron neutron capture therapy (BNCT) at kyoto university - From reactor-based BNCT to accelerator-based BNCT
}

\section{$\operatorname{AUTHOR}(S):$}

Sakurai, Yoshinori; Tanaka, Hiroki; Takata, Takushi;

Fujimoto, Nozomi; Suzuki, Minoru; Masunaga, Shinichiro; Kinashi, Yuko; ... Watanabe, Tsubasa; Ono, Koji; Maruhashi, Akira

\section{CITATION:}

Sakurai, Yoshinori ... [et al]. Advances in boron neutron capture therapy (BNCT) at kyoto university - From reactor-based BNCT to accelerator-based BNCT. Journal of the Korean Physical Society 2015, 67(1): 76-81

\section{ISSUE DATE:}

2015-07

URL:

http://hdl.handle.net/2433/202015

\section{RIGHT:}

The final publication is available at Springer via http://dx.doi.org/10.3938/jkps.67.76.; The full-text file will be made open to the public on 28 July 2016 in accordance with publisher's 'Terms and Conditions for Self-Archiving'.; この論文は出版 社版でありません。引用の際には出版社版をご確認じ利用ください。; This is not the published version. Please cite only the published version. 


\section{Advances in Boron Neutron Capture Therapy (BNCT) at Kyoto University - From Reactor-based BNCT to Accelerator-based BNCT}

Yoshinori Sakurai, Hiroki Tanaka, Takushi Takata, Nozomi Fujimoto, Minoru Suzuki, Shinichiro Masunaga, Yuko Kinashi, Natsuko Kondo, Masaru Narabayashi, Yosuke Nakagawa, Tsubasa Watanabe, Koji Ono and Akira Maruhashi

Kyoto University Research Reactor Institute, Asashiro-nishi 2-1010, Kumatori-cho, Sennan-gun, Osaka 590-0494, Japan

At the Kyoto University Research Reactor Institute (KURRI), a clinical study of boron neutron capture therapy (BNCT) using a neutron irradiation facility installed at the research nuclear reactor has been regularly performed since February 1990. As of November 2014, 510 clinical irradiations were carried out using the reactor-based system. The world's first accelerator-based neutron irradiation system for BNCT clinical irradiation was completed at this institute in early 2009, and the clinical trial using this system was started in 2012. A shift of BCNT from special particle therapy to a general one is now in progress. To promote and support this shift, improvements to the irradiation system, as well as its preparation, and improvements in the physical engineering and the medical physics processes, such as dosimetry systems and quality assurance programs, must be considered. The recent advances in BNCT at KURRI are reported here with a focus on physical engineering and medical physics topics.

Keywords: Boron neutron capture therapy, BNCT, Reactor-based system, Accelerator-based system 


\section{INTRODUCTION}

Boron neutron capture therapy (BNCT) is a noninvasive therapeutic modality for treating locally invasive malignant tumors [1]. It is performed according to a two-step procedure: (1) the patient is injected with a tumor-localizing drug containing boron, and (2) the target volume is irradiated with thermal or epi-thermal neutrons. In this therapy, the following nuclear reaction is used:

$$
\begin{gathered}
{ }^{10} \mathrm{~B}+\mathrm{n} \rightarrow{ }^{7} \mathrm{Li}+\alpha+2.79 \mathrm{MeV}(6.1 \%) \\
\rightarrow{ }^{7} \mathrm{Li}^{*}+\alpha+2.31 \mathrm{MeV}(93.9 \%) \\
\rightarrow{ }^{7} \mathrm{Li}+\gamma+0.48 \mathrm{MeV}
\end{gathered}
$$

The ranges of the $\alpha$ and the Li-7 particles generated in this reaction are approximately 8 and $5 \mu \mathrm{m}$ in tissue, respectively. The world's first clinical irradiation using BNCT was carried out using a neutron irradiation field installed at a research nuclear reactor in the USA in 1951 [2]. From 1951 until 2012, BNCT has only been performed using reactor-based irradiation systems [3-12].

At the Kyoto University Research Reactor Institute (KURRI), BNCT clinical studies using a thermal neutron irradiation facility installed at the Kyoto University Reactor (KUR) came to be regularly performed from February 1990. At first, BNCT at this institute was performed only for malignant brain tumors with a craniotomy and for malignant melanomas [13]. The application was extended to head and neck tumors in 2001 [14], to brain tumors without a craniotomy in 2002 [15], and to body tumors such as those in the liver, lung, and malignant pleural mesothelioma in $2005[16,17]$. It may be said that the current development of BNCT is supported by these wider applications. Although there were several interruption periods, 510 clinical irradiations had been carried out using this reactor-based system as of November 2014.

Concurrently with the clinical study using this reactor-based system, the development of the accelerator-based system has been on-going [18-22]. In early 2009, the world's first accelerator-based system for BNCT clinical irradiations, known as the "Cyclotron-Based Epi-thermal Neutron Source" (C-BENS) was completed [23]. The clinical trial using C-BENS was started in 2012.

At present, research and development of accelerator-based irradiation systems for BNCT are underway at several institutions [24-27]. In Japan, BNCT using various accelerator-based irradiation systems including C-BENS may be carried out at multiple facilities in the near future. Clearly, a shift of BCNT from special particle therapy to a general one is in progress. To promote and support this shift, improvements to the irradiation system, as well as its preparation, and improvements in the physical 
engineering and the medical physics processes, such as dosimetry systems and quality assurance programs, must be considered. In this paper, the history and recent advances in BNCT at KURRI are reported with a focus on physical engineering and medical physics topics.

\section{HISTORY OF BNCT AT KURRI}

KURRI was established in 1963. The first clinical study of BNCT at the thermal neutron irradiation facility at the KUR was performed in May 1974 [28]. Regular BNCT clinical irradiations at this facility started in February 1990. Sixty-one BNCT clinical irradiations were performed during the 6 years until November 1995. In the period from 1974 to 1995, only thermal neutron irradiations could be performed at this facility, so BNCT was only applied in cases of malignant melanomas and brain tumors with a craniotomy.

From 1995 to 1996, the thermal neutron irradiation facility at the KUR was remodeled into the Heavy Water Neutron Irradiation Facility (HWNIF) to advance BNCT [7]. At the remodeled facility, neutron irradiations for various neutron energy spectra from almost-pure thermal to epi-thermal became available.

The BNCT clinical study using solo-irradiations with thermal neutrons was restarted in November 1996. Mixed irradiations using thermal and epi-thermal neutrons were started in 1997. Twenty-one BNCT clinical irradiations were performed during the 5 years until June 2001. From 1996 to 2001, BNCT using thermal neutrons was applied to treat malignant melanomas, and BNCT using the mixed neutron irradiation mode was applied to treat brain tumors with a craniotomy.

In December 2001, the first BNCT treatment in the world for a head and neck tumor was carried out by using epi-thermal neutrons [14]. In June 2002, BNCT for brain tumors without a craniotomy began [15]. In 2005, wider application was promoted for tumors of the body such as tumors in the liver and the lung $[16,17]$. During the 5 years until the KUR operation was stopped for the fuel change in February 2006, 193 BNCT treatments were performed.

In February 2006, the KUR operation was stopped to change from highly-enriched uranium fuel to the low-enriched fuel [29]. During the operation stoppage, some minor changes to the HWNIF were carried out. Concurrently, the world's first cyclotron-based irradiation system practical for BNCT (CBENS) was installed at our institute in 2009 [23].

In May 2010, BNCT clinical irradiations began simultaneously with the restart of the KUR operation. After the restart, 235 BNCT irradiations had been carried out as of November 2014. The clinical trial 
using C-BENS was also started in 2012. The annual change in the number of accumulated BNCT irradiations using the reactor-based system in the KURRI is shown in Fig. 1.

\section{NEUTRON IRRADIATION SYSTEMS}

Figure 2 shows an outline of the advanced irradiation system for BNCT installed at the KUR concurrent with the remodeling of the KUR-HWNIF from 1995 to 1996 [7]. Clinical irradiations under the 5-MW full-power continuous KUR operation can be performed by employing a radiation shielding system consisting of the shielding door, the irradiation room, and the remote carrying system for the patient.

The KUR-HWNIF has a heavy-water tank of approximately $2 \mathrm{~m}^{3}$ adjacent to the KUR core. The heavy-water tank contains an aluminum-heavy water mixture, and a neutron-energy spectrum shifter of heavy water with a thickness varying from 0 to $90 \mathrm{~cm}$ in order from the core side. Outside the spectrum shifter, two thermal neutron filters of 1-mm-thick cadmium are installed. The energy spectrum of the neutron beam can be controlled from almost pure thermal to epi-thermal within 5 minutes by remote control under continuous reactor operation [30].

As described above, the KUR operation stopped from February 2006 to May 2010 for a change from highly-enriched uranium fuel to low-enriched fuel [29]. Table 1 shows the beam characteristics at 5 MW of KUR power after installation of the low-enriched fuel for three irradiation modes: thermal, epithermal, and a mixture of thermal and epi-thermal neutrons. Here, the energy ranges are $<0.5 \mathrm{eV}$ for thermal neutrons, $0.5 \mathrm{eV}$ to $10 \mathrm{keV}$ for epi-thermal neutrons, and $>10 \mathrm{keV}$ for fast neutrons. The maximum change in the irradiation characteristics for the main irradiation modes with the low-enriched fuel was experimentally shown to be $20 \%$. Also, we specifically confirmed that the beam quality changes for the fast-neutron and the gamma-ray contaminations were within $\pm 10 \%$ and hardly influenced the BNCT clinical irradiation results.

For the irradiation system using an accelerator, the neutron source changes from the reactor core to an accelerator target. The basic concept of neutron generation is similar between reactor-based systems and accelerator-based systems. The selection of key parameters, such as the nuclear reaction, type of accelerating particle, and accelerating energy, is important to consider. Many references describe the selection of neutron sources and accelerating particles and energies for BNCT [23-27, 31-35]. Specifically, the reaction of lithium or beryllium with a proton is thought to be more adequate for BCNT neutron generation because of the generated neutron energy and neutron yield.

For the C-BENS, the nuclear reaction of ${ }^{9} \mathrm{Be}(\mathrm{p}, \mathrm{xn}){ }^{9} \mathrm{~B}$ with $30-\mathrm{MeV}$ protons was selected [23]. 
Figure 3 shows an outline of the C-BENS. The high-energy neutrons generated from this reaction are moderated to thermal and epi-thermal neutrons through a moderator consisting of lead, iron, aluminum, and calcium-fluoride. The incident thermal neurons and gamma-rays are reduced by cadmium and lead filters, respectively, resulting in an epi-thermal neutron beam adequate for BNCT.

Table 2 compares the characteristics of the epi-thermal neutron mode of the KUR-HWNIF with that of the C-BENS. The beam quality of C-BENS is a little better because of the smaller contamination of fast neutrons and gamma-rays, and the epi-thermal neutron intensity is over two times larger than that of the KUR-HWNIF. The energy spectrum of the neutron beam from the C-BENS is harder than that from the KUR-HWNIF. The physical facilities are essentially the same as the BNCT facility; however, the KUR-HWNIF is used for research, and the C-BENS is intended for clinical use only.

\section{BEAM CHARACTERIZATION}

For beam characterization, the neutron energy spectrum is conventionally estimated by using the multi-activation foil method for two main reasons [30]. The first reason is that the activation foils are small and do not perturb the irradiation field. The second reason is that the desired nuclear reactions can be selected according to the neutron energy range. However, estimating the neutron energy spectrum in the $\mathrm{keV}$ range is difficult by using this method.

In the KURRI, Bonner's ball method is applied to supplement the multi-activation foil method [36]. In this method, the moderation material and wall thickness can be chosen for the neutron energy range. Activation foils, mainly for the thermal neutron range, and/or a He-3 counter are used as the detector. In contrast to the multi-activation foil method, the Bonner's ball detector is large enough to perturb the field, and the detector response function should be determined by simulation.

For the estimate of the primary gamma-ray dose rate, a smaller detector is desired so as not to perturb the field, similarly to that of the neutron energy spectrum. Thermo-luminescent dosimeters (TLD) and/or glass detectors are commonly used for this purpose. Many kinds of TLD are well known to exhibit an energy response to neutrons, and a correction for this must be applied. A special type of TLDs, BeO enclosed in a quartz glass capsule, is used at KURRI [30].

Ionization chambers are also used in the measurement of neutron and gamma-ray dose rates, typically as online detection systems. The four main beam components, thermal neutrons, epi-thermal neutrons, fast neutrons, and gamma-rays, are measured separately. Chambers are selected while considering the neutron energy spectrum and the mixing ratio of gamma-rays. The wall material, wall thickness, and ionization gas are also selected for the four components. Typical wall materials include 
$\mathrm{Si}_{3} \mathrm{~N}_{4}$, polyethylene, graphite, and magnesium. A coating of Li-6-enriched $\mathrm{LiF}$ may be applied as needed. Typical ionization gasses used are $\mathrm{CO}_{2}, \mathrm{~N}_{2}$, tissue equivalent gas, $\mathrm{CH}_{4}$ and Ar. When ionization chambers are used to measure the neutron dose rate, the chamber perturbation should be considered.

Recently, the authors reported on developing a multi-ionization chamber system (MICS), as seen in Fig. 4 [37]. The wall material, wall thickness, and ionization gas are selected specially for each component as follows: (1) a $\mathrm{Si}_{3} \mathrm{~N}_{4}$ wall and $\mathrm{N}_{2}$ gas for thermal neutrons, (2) a $\mathrm{Si}_{3} \mathrm{~N}_{4}$ wall coated with LiF enriched with Li-6 and $\mathrm{N}_{2}$ gas for epi-thermal neutrons, (3) a polyethylene wall and $\mathrm{CH}_{4}$ gas for fast neutrons, and (4) a graphite wall and argon gas for gamma-rays. Signals from the four chambers are arithmetically operated on with Cramer's formula.

Activation foils and TLDs are commonly used to estimate the dose distribution in-phantom [38]. Au foils with and without a Cd cover are typically used for thermal and epi-thermal neutrons and $\mathrm{In}, \mathrm{Ni}$, and $\mathrm{Al}$ foils are used for fast neutrons. We should note that TLDs cannot be placed near the activation foils because the secondary gamma-rays generated from the foils would influence the TLD measured data. In addition to foils and TLDs, some studies have reported on the use of ionization chambers and scintillating fibers in the measurement of the dose in-phantom [39].

\section{DOSE MONITORING UNDER IRRADIATION}

A MICS can also be used as a beam monitor system [37]. As described above, a MICS can monitor the changes in the beam characteristics by using four types of ionization chambers to separate and resolve the four beam components by using Cramer's formula. This system is almost complete and will be used under BNCT irradiations at the KUR-HWNIF in the near future.

For the measurement of the surface dose, a mixture of incident epi-thermal neutrons and thermal neutrons moderated in the patient must be considered. Separate measurements are necessary to monitor the intensity of the incident epi-thermal neutrons. The activation foil method using $\mathrm{Au}$ and $\mathrm{Mn}$, as well as TLDs, is commonly used in the measurement of surface dose during epi-thermal neutron irradiation. Surface dose measurements using an online scintillating optical fiber have also been reported [39].

The B-10 concentration is changed according to the elapsed time. The change in the concentration is larger for the patients. Then, the B-10 concentration under irradiation must be estimated. Presently, prompt gamma-ray analysis (PGA) is used [40]. Figure 5 shows a schematic of the PGA system using the neutron guide tube at the KUR. Blood samples are obtained from the patient at several time points 
after injection with the boron compound, and the average B-10 concentration is estimated from the PGA.

Some online systems for estimating the B-10 concentration, such as prompt gamma-ray SPECT (PGSPECT), have been studied [41]. In this system, many gamma-ray detectors with high-energy resolution, strong neutron shielding, and precision collimator positioning are needed. As such, development of this system is technologically limited at present.

Gamma-ray telescopes have also been investigated for use in online B-10 concentration detection. Figure 6 shows the gamma-ray telescope system installed at the KUR-HWNIF [20]. In this telescope system, two units are installed. During scanning, one unit is focused on the area where the tumor is, while the other is focused on the normal region of the body. Currently, the gamma-ray telescope system at the KURRI is used for liver-tumor BNCT [16].

\section{CONCLUSION}

The recent advances in BNCT at KURRI were reported, focusing on topics for physical engineering and medical physics. Two BNCT neutron irradiation facilities at KURRI, KUR-HWNIF and C-BENS, were introduced. Beam characterization and online monitoring methods were introduced. As the field of BNCT advances, further development of online systems is expected.

Many plans for accelerator-based BNCT systems are taking shape, but these plans have not yet been put into action. Recently, several research reactors have been shut down, leaving little opportunity for new research reactors to be constructed. Presently, BNCT is only performed at three institutes: KURRI in Japan, the National Atomic Energy Commission in Argentina, and the National Tsing Hua University in Taiwan. At the latter two institutes, only reactor-based systems are used. Shifting from reactor-based $\mathrm{BNCT}$ to accelerator-based $\mathrm{BNCT}$ should be promoted as soon as possible.

\section{ACKNOWLEDGMENTS}

Research and clinical studies of BNCT are supported by the collaborations of several universities and institutes such as the Osaka Medical College, Kawasaki Medical School, Osaka University, University of Tsukuba, and The University of Tokyo. The authors thank all of these collaborators.

\section{REFERENCES}

[1] G. L. Locher, Am. J. Roentgenol. 36, 1 (1936). 
[2] L. E. Farr, W. H. Sweet, J. S. Robertson, C. G. Foster, H. B. Locksley, D. L. Suntherland, M. L. Mendelsohn and E. E. Stickly, Am. J. Roentgenol. 71, 279 (1954).

[3] H. Hatanaka and K. Sano, Z. Neurol. 204, 309 (1973).

[4] H. Hatanaka, K. Amano, S. Kamano, F. Tovaryš, N. Machiyama, T. Matsui, H. Fankhauser, T. Hanamura, T. Nukada, et al., Modern Neurosurgery 1, M. Brock (Ed.) (Springer-Verlag, Berlin, 1982), p. 122.

[5] O. K. Harling, J. C. Yanch, J. R. Choi, G. R. Solares, R. D. Rogus, D. J. Moulin, L. S. Johnson, I. Olmez, S. Wirdzek, J. A. Bernard, et al., Nucl. Sci. Eng. 110, 330 (1992).

[6] K. Yokoo, T. Yamada, F. Sakurai, T. Nakajima, N. Ohhashi and H. Izumo, Advances in Neutron Capture Therapy, Vol. I, Medicine and Physics, B. Larsson, et al. (Eds.) (Elsevier, Amsterdam, 1997), p. 326.

[7] Y. Sakurai and T. Kobayashi, Nucl. Instr. Meth. A 453, 569 (2000).

[8] J. Burian, M. Marek, J. Rataj and S. Flibor, IAEA-TECDOC-1223, 126 (2001).

[9] H. Joensuu, L. Kankaanranta, T. Seppala, I. Auterinen, M. Kallio, M. Kulvik, J. Laakso, J. Vahatalo, M. Kortesniemi and S. Savolainen, J. Neuro. Oncol. 62, 123 (2003).

[10] S. J. Gonzalez, M. R. Bonomi, G. A. Santa Cruz, H. R. Blaumann, O. A. Calzetta Larrieu, P. Menendez, R. Jimenez Rebagliati, J. Longhino, D. B. Feld and B. M. Roth, Appl. Radiat. Isot. 61, 1101 (2004).

[11] V. Nievaart, A. Wittig, R. Moss, J. Rassow and W. Sauerwein, Strahlenther. Onkol. 182, 109 (2006).

[12] L. W. Wang, S. J. Wang, P. Y. Chu, C. Y. Ho, S. H. Jiang, Y. W. Liu, Y. H. Liu, H. M. Liu, J. J. Peir, et al., Appl. Radiat. Isot. 69, 1803 (2011).

[13] H. Hatanaka, Y. Nakagawa and S. Sakai, Advances in Neutron Capture Therapy, A. H. Soloway, et al. (Eds.) (Plenum Press, New York, 1993), p. 699.

[14] I. Kato, Y. Fujita, A. Maruhashi, H. Kumada, M. Ohmae, M. Kirihata, Y. Imahori, M. Suzuki, Y. Sakurai, et al., Appl. Radiat. Isot. 67, S37 (2009).

[15] S. Kawabata, S. Miyatake, N. Nonoguchi, R. Hiramatsu, K. Iida, S. Miyata, K. Yokoyama, A. Doi, Y. Kuroda, et al., Appl. Radiat. Isot. 67, S15 (2009).

[16] M. Suzuki, Y. Sakurai, S. Hagiwara, S. Masunaga, Y. Kinashi, K. Nagata, A. Maruhashi, M. Kudo and K. Ono, Jpn. J. Clin. Oncol. 37, 376 (2007).

[17] M. Suzuki, K. Endo, H. Satoh, Y. Sakurai, H. Kumada, H. Kimura, S. Masunaga, Y. Kinashi, K. Nagata, et al., Radiother. Oncol. 88, 192 (2008).

[18] K. Tanaka, T. Kobayashi, Y. Sakurai, Y. Nakagawa, S. Endo and M. Hoshi, Phys. Med. Biol. 
46, 2681 (2001).

[19] K. Tanaka, T. Kobayashi, Y. Sakurai, Y. Nakagawa, M. Ishikawa and M. Hoshi, Phys. Med. Biol. 47, 3011 (2002).

[20] Y. Sakurai, A. Maruhashi and K. Ono, Appl. Radiat. Isot. 61, 829 (2004).

[21] Y. Sakurai and A. Maruhashi, Nucl. Instr. Meth. A 562, 1046 (2006).

[22] T. Takata, H. Tanaka, Y. Sakurai and A. Maruhashi, J. Nucl. Sci. Technol. 47, 575 (2010).

[23] H. Tanaka, Y. Sakurai, M. Suzuki, S. Masunaga, Y. Kinashi, G. Kashino, Y. Liu, T. Mitsumoto, S. Yajima, et al., Nucl. Instr. Meth. B 267, 1970 (2009).

[24] C. N. Culbertson, S. Green, A. J. Mason, D. Picton, G. Baugh, R. P. Hugtenburg, Z. Yin, M. C. Scott and J. M. Nelson, Appl. Radiat. Isot. 61, 733 (2004).

[25] C. Ceballos, J. Esposito, S. Agosteo, P. Colautti, V. Conte, D. Moro, A. Pola, Appl. Radiat. Isot. 69, 1660 (2011).

[26] A. J. Kreiner, W. Castell, H. Di Paolo, M. Baldo, J. Bergueiro, A. A. Burlon, D. Cartelli, V.

Thatar Vento, J. M. Kesque, et al., Appl. Radiat. Isot. 69, 1672 (2011).

[27] H. Kumada, A. Matsumura, H. Sakurai, T. Sakae, M. Yoshioka, H. Kobayashi, H. Matsumoto, Y. Kiyanagi, T. Shibata and H. Nakashima, Appl. Radiat. Isot. 88, 211 (2014).

[28] K. Kanda, K. Kobayashi, S. Okamoto and T. Shibata, Nucl. Instr. Meth. 148, 535 (1978).

[29] X. Shen, K. Nakajima, H. Unesaki and K. Mishima, Ann. Nucl. Energy 62, 195 (2013).

[30] Y. Sakurai and T.Kobayashi, Nucl. Instr. Meth. A 531, 585 (2004).

[31] C. K. Wang, T. E. Blue, R. Gahbauer, Nucl. Technol. 84, 93 (1988).

[32] D. A. Allen and T. D. Beynon, Phys. Med. Biol. 40, 807 (1995).

[33] B. F. Bayanov, V. P. Belov, E. D. Bender, M. V. Bokhovko, G. I. Dimov, V. N. Kononov, O. E. Kononov, N. K. Kuksanov, V. E. Palchikov, et al., Nucl. Instr. Meth. A 413, 397 (1998).

[34] J. M. Verbeke, J. L. Vujic and K. N. Leung, Nucl. Technol. 129, 257 (2000).

[35] S. Yonai, M. Baba, T. Nakamura, H. Yokobori and Y. Tahara, J. Nucl. Sci. Technol. 45, 378 (2008).

[36] H. Ueda, H. Tanaka, A. Maruhashi, K. Ono and Y. Sakurai, Appl. Radiat. Isot. 69, 1657 (2011).

[37] T. Fujii, H. Tanaka, A. Maruhashi, K. Ono and Y. Sakurai, Appl. Radiat. Isot. 69, 1862 (2011).

[38] Y. Sakurai and T. Kobayashi, Med. Phys. 29, 2328 (2002).

[39] M. Ishikawa, K. Ono, Y. Sakurai, H. Unesaki, A. Uritani, G. Bengua, T. Kobayashi, K. Tanaka and T. Kosako, Appl. Radiat. Isot. 61, 775 (2004).

[40] T. Kobayashi and K. Kanda, Nucl. Instr. Meth. 204, 525 (1983).

[41] T. Kobayashi, Y. Sakurai and M. Ishikawa, Med. Phys. 27, 2124 (2000). 
Table 1. Beam characteristics for three irradiation modes of KUR-HWNIF at $5 \mathrm{MW}$ of KUR power after the low fuel enrichment.

\begin{tabular}{|ccccccc|}
\hline $\begin{array}{c}\text { Irradiation } \\
\text { mode }\end{array}$ & $\begin{array}{c}\text { Heavy water } \\
\text { thickness } \\
(\mathrm{cm})\end{array}$ & $\begin{array}{c}\text { Cadmium } \\
\text { ratio }\end{array}$ & $\begin{array}{c}\text { Thermal } \\
\text { neutron flux } \\
\left(\mathrm{cm}^{-2} \mathrm{~s}^{-1}\right)\end{array}$ & $\begin{array}{c}\text { Epi-thermal } \\
\text { neutron flux } \\
\left(\mathrm{cm}^{-2} \mathrm{~s}^{-1}\right)\end{array}$ & $\begin{array}{c}\text { Fast } \\
\text { neutron flux } \\
\left(\mathrm{cm}^{-2} \mathrm{~s}^{-1}\right)\end{array}$ & $\begin{array}{c}\text { Gamma-ray } \\
\text { dose rate } \\
(\mathrm{cGy} / \mathrm{h})\end{array}$ \\
\hline $\begin{array}{c}\text { Thermal } \\
\text { neutron }\end{array}$ & 30 & 150 & $1.8 \times 10^{9}$ & $1.9 \times 10^{7}$ & $3.6 \times 10^{6}$ & 160 \\
\hline $\begin{array}{c}\text { Epi-thermal } \\
\text { neutron }\end{array}$ & 0 & 1 & $3.7 \times 10^{7}$ & $9.1 \times 10^{8}$ & $5.1 \times 10^{7}$ & 70 \\
\hline $\begin{array}{c}\text { Mixed } \\
\text { neutron }\end{array}$ & 0 & 11 & $6.1 \times 10^{9}$ & $9.2 \times 10^{8}$ & $5.1 \times 10^{7}$ & 340 \\
\hline
\end{tabular}

Table 2. Comparison between the reactor-based system and the accelerator-based system at KURRI.

\begin{tabular}{|c|c|c|c|c|c|c|}
\hline Facility & Type & $\begin{array}{l}\text { Epi-thermal } \\
\text { neutron flux } \\
\left(\mathrm{cm}^{-2} \mathrm{~s}^{-1}\right)\end{array}$ & $\begin{array}{l}\text { st neutron d } \\
\text { pi-thermal } \mathrm{f} \\
\left(\mathrm{Gy} / \mathrm{cm}^{-2}\right)\end{array}$ & $\begin{array}{l}\text { pi-thermal flux } \\
\left(\mathrm{Gy} / \mathrm{cm}^{-2}\right)\end{array}$ & Purpose & BNCT application \\
\hline $\begin{array}{c}\text { KUR-HWNIF } \\
\text { (epi-thermal } \\
\text { mode) }\end{array}$ & $\begin{array}{c}\text { Reactor- } \\
\text { based }\end{array}$ & $9.1 \times 10^{8}$ & $6.1 \times 10^{-13}$ & $2.4 \times 10^{-13}$ & $\begin{array}{l}\text { Research } \\
\text { and study }\end{array}$ & $\begin{array}{l}\text { New challenge and } \\
\text { wider application }\end{array}$ \\
\hline C-BENS & $\begin{array}{l}\text { Accelerator- } \\
\text { based }\end{array}$ & $1.9 \times 10^{9}$ & $5.8 \times 10^{-13}$ & $7.8 \times 10^{-14}$ & $\begin{array}{l}\text { Clinical use } \\
\text { only }\end{array}$ & $\begin{array}{c}\text { For tumors with } \\
\text { sufficient experiments } \\
\text { and achievements at } \\
\text { KUR-HWNIF }\end{array}$ \\
\hline
\end{tabular}




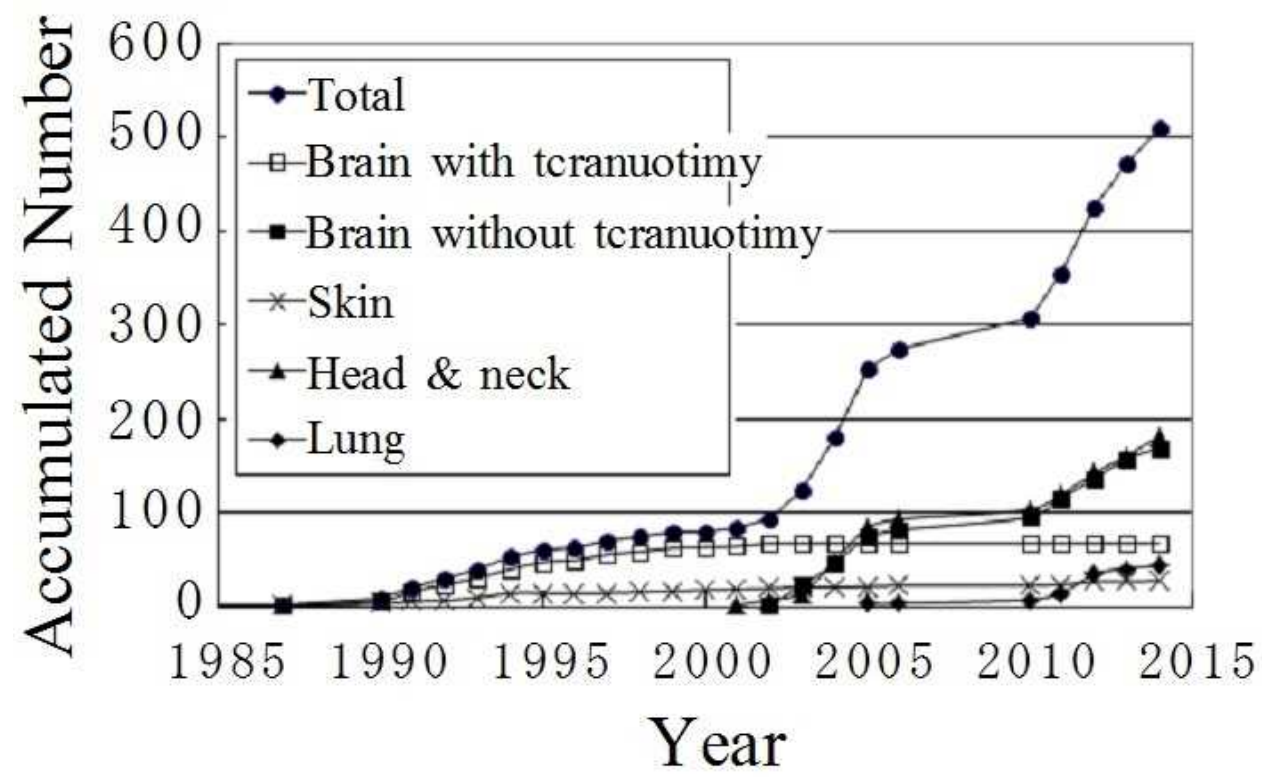

Fig. 1. Annual change in the accumulated number of BNCT irradiations at the KUR-HWNIF.

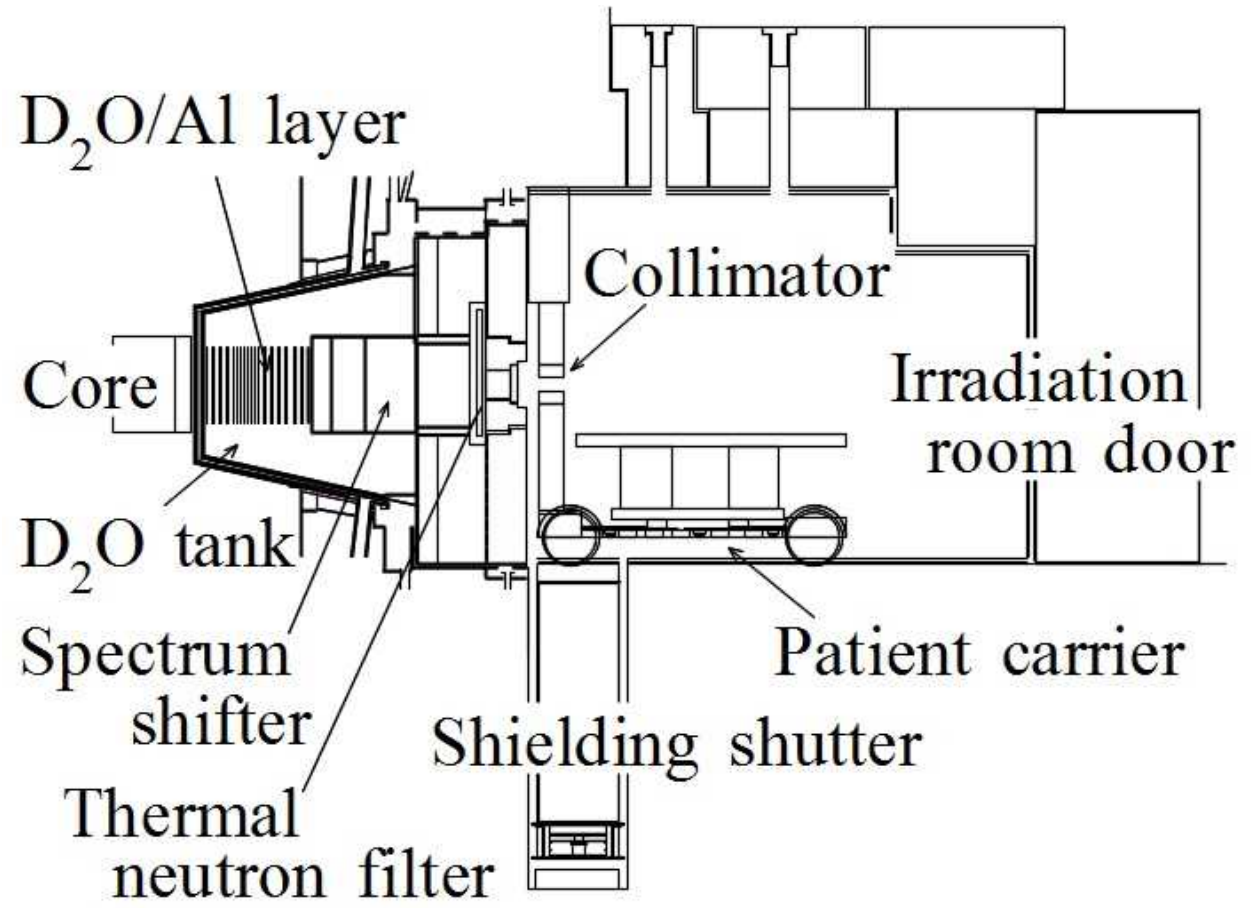

Fig. 2. Outline of the advanced irradiation system for BNCT installed in the KUR. 


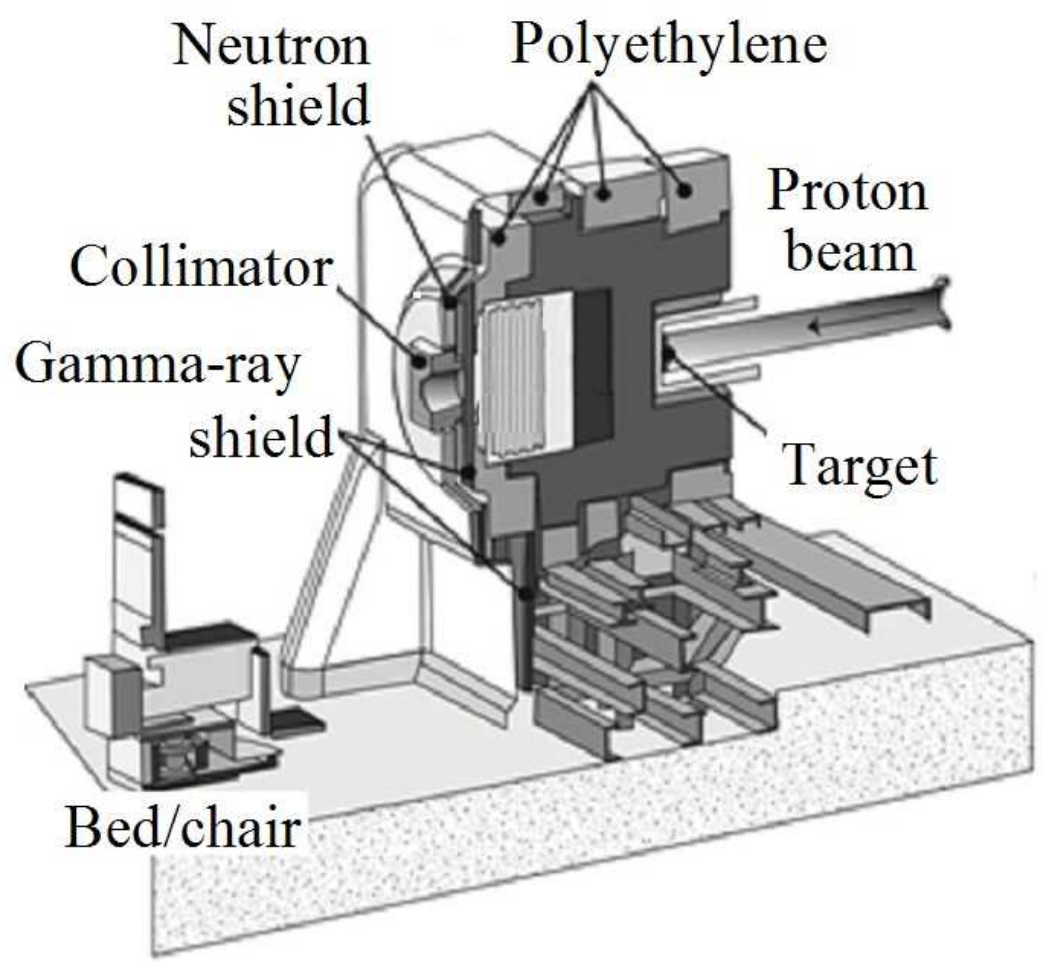

Fig. 3. Outline of the Cyclotron-Based Epi-thermal Neutron Source (C-BENS) [23].

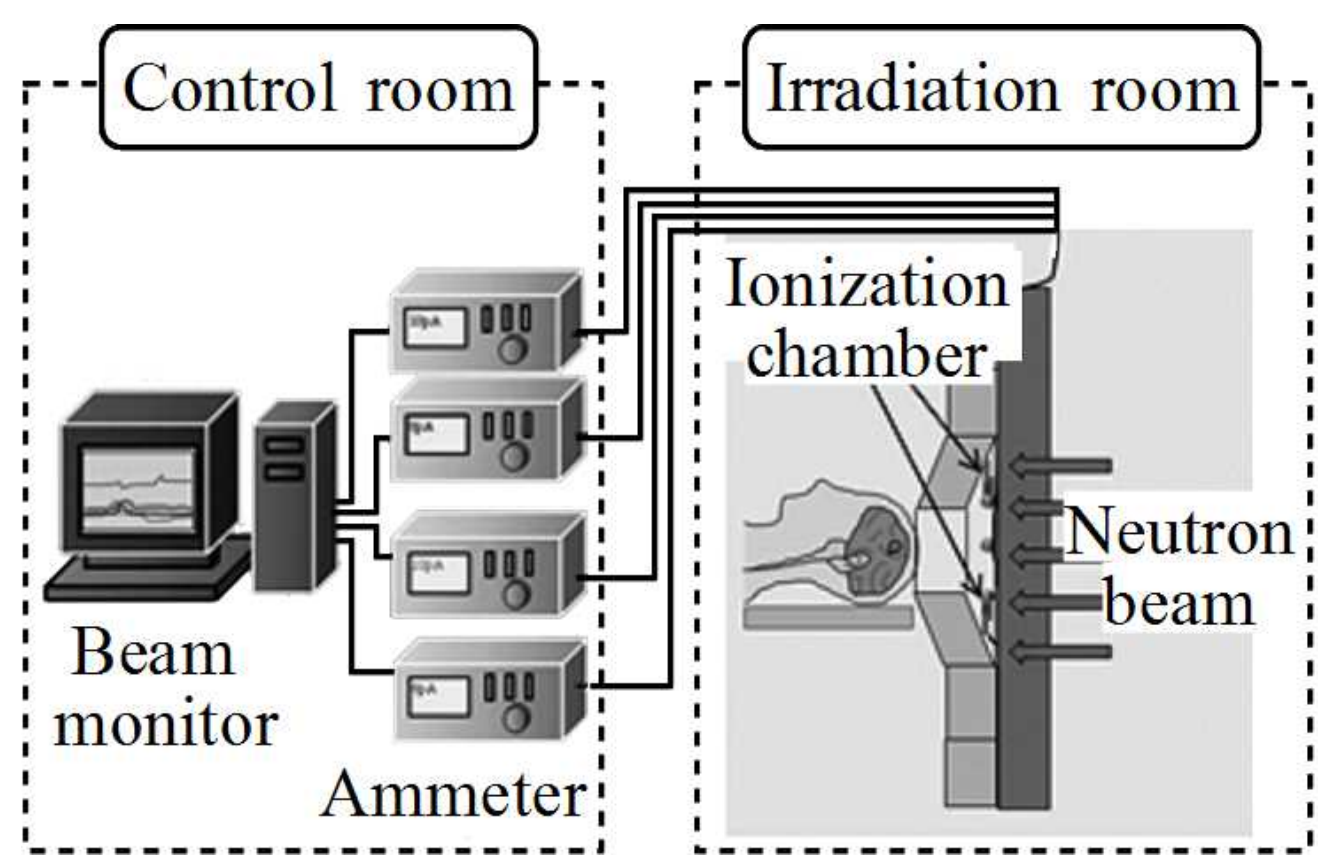

Fig. 4. Outline of the multi-ionization chamber system (MICS). 


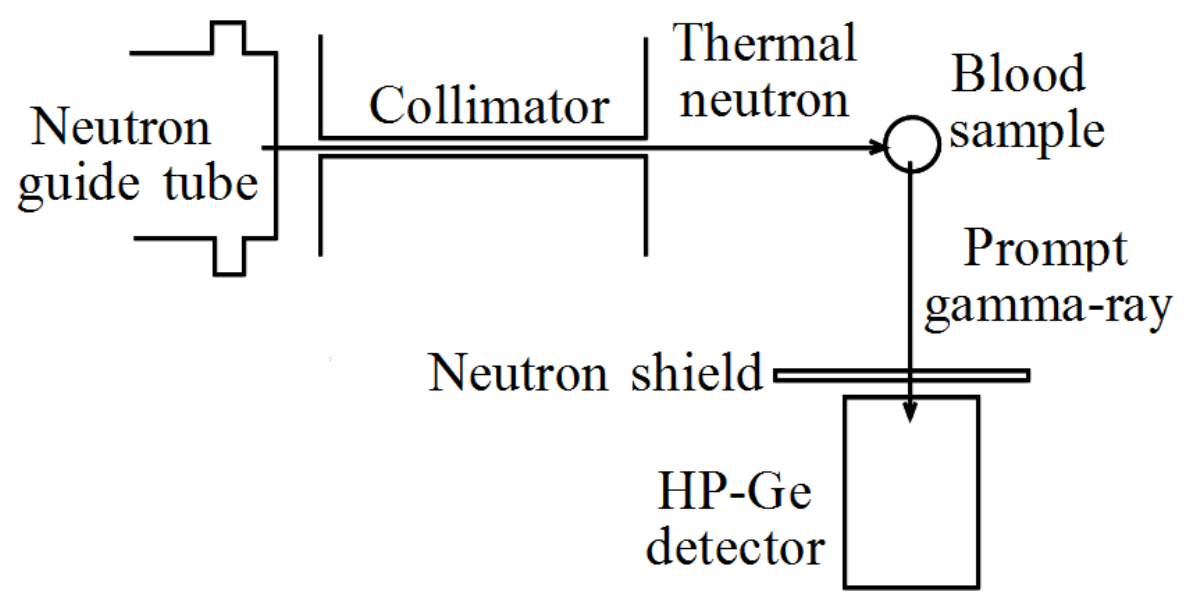

Fig. 5. Schematic of the PGA system installed in the KUR.

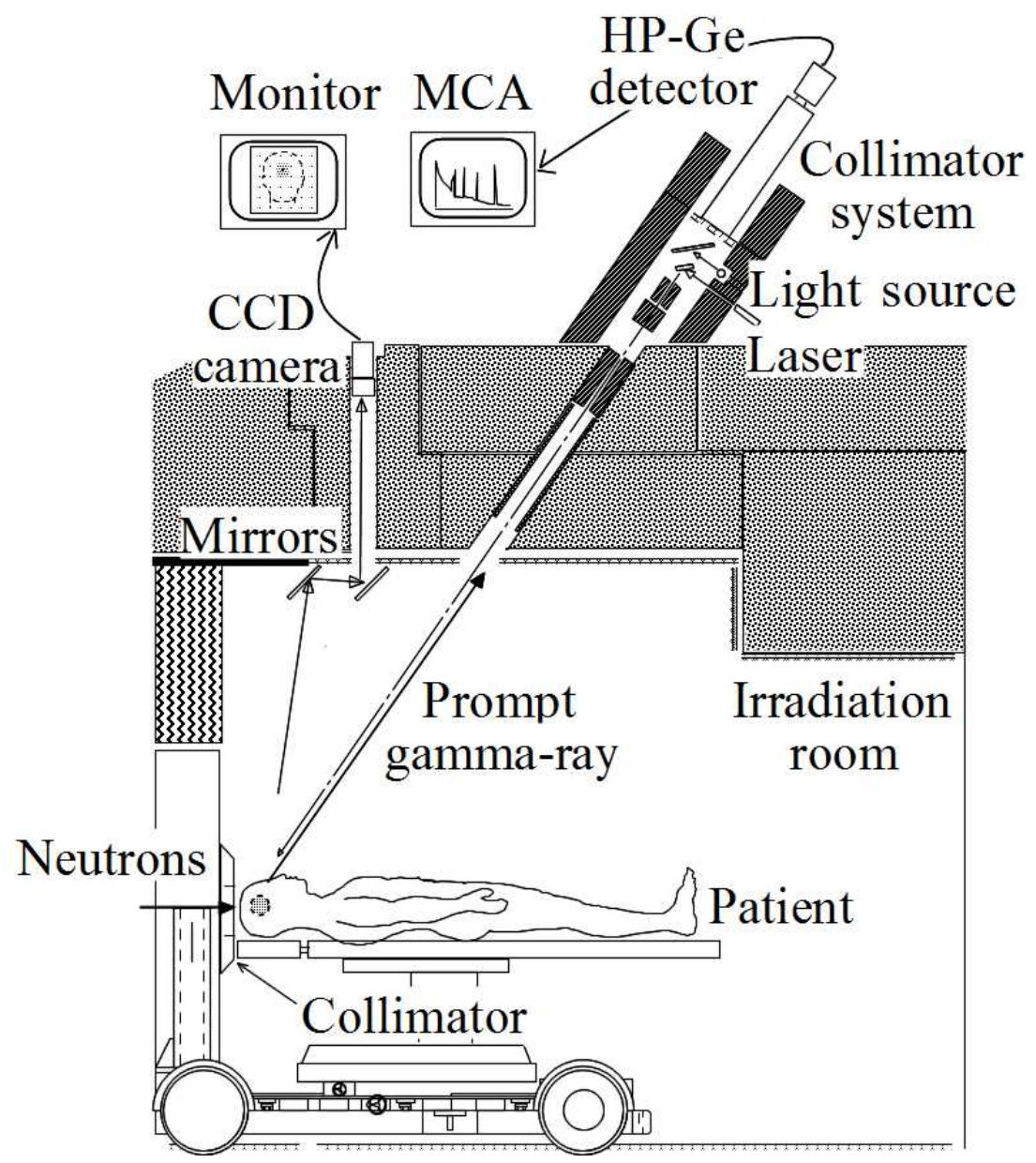

Fig. 6. Outline of the gamma-ray telescope system installed at the KUR-HWNIF [20]. 